\title{
Unemployment, Inflation and Impact of GDP in India
}

\author{
Xinhe Xia \\ Managing the Macroeconomy: Business Cycles, Monetary and Fiscal Policy, StonyBrook University, StonyBrook, \\ New York State, 11790, U.S. \\ Corresponding author's e-mail: ShiLiShuang@cas-harbour.org
}

\begin{abstract}
Inflation and lack of employment are primary challenges that affect every economy in all developing countries. This article's research topic evaluates the rate of lack of employment and inflation in the Indian economy in six years to determine a trade-off between inflation and lack of employment. A reversed association between the inflation rate and the rate of lack of employment exists; an increment in inflation drives a reduction in lack of employment and vice versa. The research uses the Bi-variants analysis method, where the rate of lack of employment is the variable in the first theory and the inflation rate in the second. The main instrument used in this study is the Phillips curve. The curve examines the connection between the lack of employment and the rate in which the wage changes. The data is gathered in the U.K from 2001 to 2015s [3]. The study's results proved that lack of employment influenced inflation. The lack of employment is a frequently occurring circumstance in the economies of all developing countries. It positively affects the GDP, living standards among people, and the price levels. The results showed a significant association between inflation and lack of employment, but the relationship is insignificant in India's economy. The main implication of these findings is that policymakers should focus on efforts towards reorganizing the economy, the level of employment, and managing the instability in prices.
\end{abstract}

Keywords: Bi-variate regression model, Real GDP, Lack of employment, Short-run Philips curve, Inflation

\section{INTRODUCTION}

Inflation is the increase in the prices of goods in a country's economy. The Phillips curve was established in 2001 to 2015 by Phillips [3]. The curve shows hostile relations between the inflation rate and lack of employment. The first challenge to be explored will be inflation in India's economy, where it deteriorates the value of money, restricting people to minimize their stock of cash. Sellers usually use resources to modify prices when they rise. As a result, society's output decreases by dedicating the resources to changing prices [7]. India's lack of employment issue results from the loss in production since this unemployed workforce does not contribute to production. Besides, these people do not pay taxes, forcing taxpayers to bear their output costs. As a result, the development of strategic analysis to carb the inflation and unemployment is to be investigated.

The method used in estimation is the Bi-variate regression model approach. The data used for this research is gathered from the U.K 1960s [3]. The information includes; data on the lack of employment rate (ER), the GDP, and inflation of the consumer price
(IP) [2]. The study on the relationship between the lack of employment and India's economy's inflation rate is done by employing the regression theory. The GDP and inflation are regressed on a lack of employment in the theory of GDP-Inflation to determine how the explained variable is affected by the explanatory variables [2]. The second model regresses, that is, employment and inflation model, the GDP lack, while the third theory, that is, GDP- employment regresses in lack of inflation. This research's alternative hypothesis states a substantial relationship between the unemployment and India's inflation rate [7]. The null hypothesis says that there is no significant correlation between inflation and lack of employment in India. Thus, the strategy involved is to evaluate the causes of the hiccup through interview and use of secondary data to predict the trend.

\section{LITERATURE REVIEW}

The Phillips curve usually shows a reverse association between the lack of employment rate and the rate in which wages increase. The major issue is employment and inflation raise leading to high-level of economic unsustainability. The study found a consistent 
reverse relationship where IP lack of employment increases, wages tend to increase gradually, and when lack of employment is low, they rise rapidly [7]. The curve indicates an average link between the behavior of wages and lack of employment in the economy. It shows the wage inflation rate that can result from a specific lack of employment level in a certain period. Various economists have studied the curve after Philip, and some refute it while others validate it. Chander (2020) represented a monetarist perspective on the Phillips curve, which showed no trade-off between the lack of employment and inflation rate in the long run. In his argument, any attempt to manipulate the lack of employment at low levels artificially usually leads to an increase in inflation. Basically, to retrieve the condition, the investment and establishment of industrial production aiding controlling inflation as well as unemployment.

\section{METHODOLOGY}

The three theories can be represented in the functional form of the analysis with: EUR $=r$ (IP, GDP),
$\mathrm{IP}=\mathrm{r}(\mathrm{EUR}, \mathrm{GDP})$, and GDP $=\mathrm{r}(\mathrm{EUR}, \mathrm{IP})$, where $\mathrm{r}$ is the functional connection. When the model is expanded into a linear link it is represented as follows

$$
\begin{aligned}
& \mathrm{EUR}=\mu 0+\mu 1 \mathrm{GDP}+\mu 2 \text { IP } \\
& \mathrm{IP}=\mu 0+\mu 1 \quad \mathrm{EUR}+\mu 2 \text { GDP } \\
& \mathrm{GDP}=\mu 0+\mu 1 \mathrm{EUR}+\mu 2 \mathrm{IP}
\end{aligned}
$$

The econometrics theory is represented as follows:

$$
\begin{aligned}
& \mathrm{EUR}=\mu 1+\mu 1 \mathrm{GDP}+\mu 2 \mathrm{IP}+\text { et } \\
& \mathrm{IP}=\mu 0+\mu 1 \mathrm{EUR}+\mu 2 \mathrm{GDP}+\text { et } \\
& \mathrm{RGDP}=\mu 0+\mu 1 \mathrm{EUR}+\mu 2 \mathrm{IP}+\text { et }
\end{aligned}
$$

Where $\mu 0$ illustrates the lack of employment in the first theory, inflation in the second, and the third theory's GDP when the variables are equal to zero. The purpose of the stochastic term (et) is to grasp the effect of other variables not inclusive in the theories [5].

Table 1. Analysis of regression between real GDP, lack of employment, and inflation.

\begin{tabular}{|c|c|}
\hline \multicolumn{2}{|c|}{ Regressing Real GDP and inflation on EUR from 2001 to 2007 in theory one } \\
\hline $\mathrm{R}^{2}$ & ${\text { Modified } \mathrm{R}^{2}}^{2}$ \\
\hline 0.76 & 0.61 \\
\hline Regressing the GDP and EUR on inflation from 2001 to 2007 in theory two \\
\hline $\mathrm{R}^{2}$ & Modified $\mathrm{R}^{2}$ \\
\hline 0.95 & 0.94 \\
\hline Regressing Real GDP and EUR on inflation from 2001 to 2007 in theory three \\
\hline $\mathrm{R}^{2}$ & Modified $\mathrm{R}^{2}$ \\
\hline 0.96 & 0.92 \\
\hline
\end{tabular}

Table 1 explains the relation between the lack of employment and the inflation rate. The results show a 0.7 percent variation in the variable real GDP influenced by inflation. These findings indicate that the theory is not satisfactory. According to Chander's (2020) study, a 0.95 percent variation in the lack of employment is affected by inflation. Chander's research also finds that a 0.95 percent variation in the quality of inflation results from a lack of employment.

\section{ANALYSIS}

\subsection{The Rate of Inflation in India from 2001} To 2007

Table 2. The rate of inflation of the Indian economy from 2001 to 2007.

\begin{tabular}{|c|c|}
\hline Years & The rate of inflation (percentage) \\
\hline $2001-2002$ & 10.90 \\
\hline $2002-2003$ & 12.09 \\
\hline $2003-2004$ & 9.21 \\
\hline $2004-2005$ & 7.65 \\
\hline
\end{tabular}




\begin{tabular}{|c|c|}
\hline $2005-2006$ & 6.02 \\
\hline $2006-2007$ & 7.12 \\
\hline
\end{tabular}

Source: Worldwide Inflation.

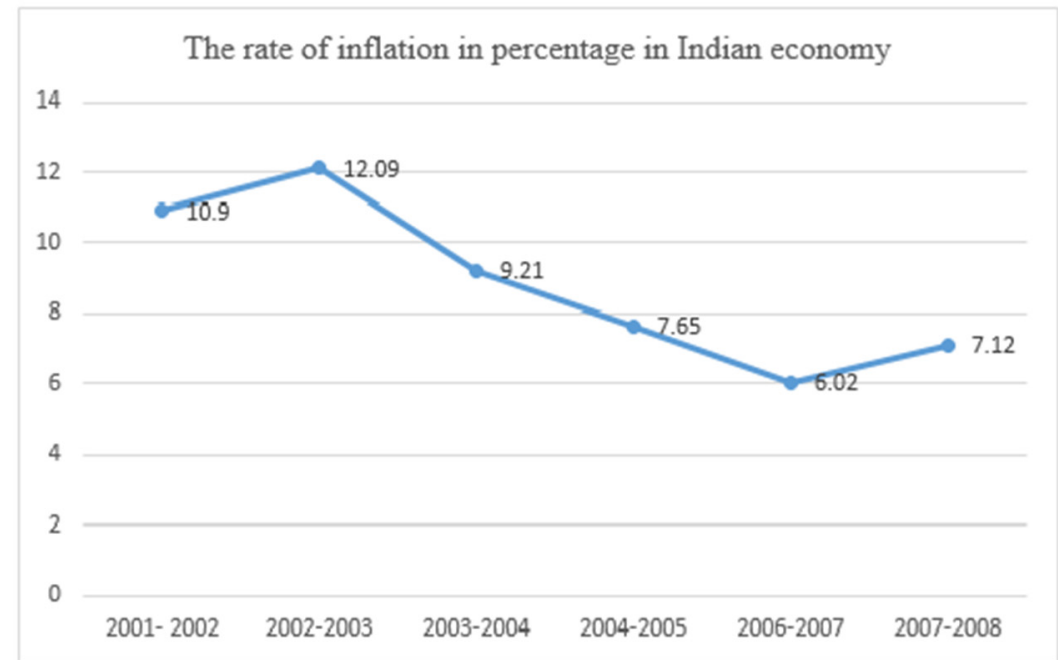

Figure 1 The rate of inflation of Indian economy from 2001 to 2007

From 2002 to 2003 , the inflation rate increased by 1.19 percent and decreased by 2.88 percent from 2003 to 2004. It fell continuously and reaches to 7.12 percent from 2006 to 2007 . The above data enable the study to conclude that the Indian economy's inflation sometimes decreases and sometimes increases; it fluctuates but not linearly [1].
4.2. The Rate of Lack of Employment in the Indian Economy from 2001 to 2007.

Table 3. The rate of lack of employment in the Indian economy from 2001 to 2007.

\begin{tabular}{|c|c|}
\hline Years & The rate of lack of employment (percentage) \\
\hline $2001-2002$ & 10.20 \\
\hline $2002-2003$ & 10.90 \\
\hline $2003-2004$ & 9.9 \\
\hline $2004-2005$ & 8.7 \\
\hline $2005-2006$ & 9.0 \\
\hline $2006-2007$ & 7.5 \\
\hline
\end{tabular}

Source: The Ministry of Labor and Employment; India. 


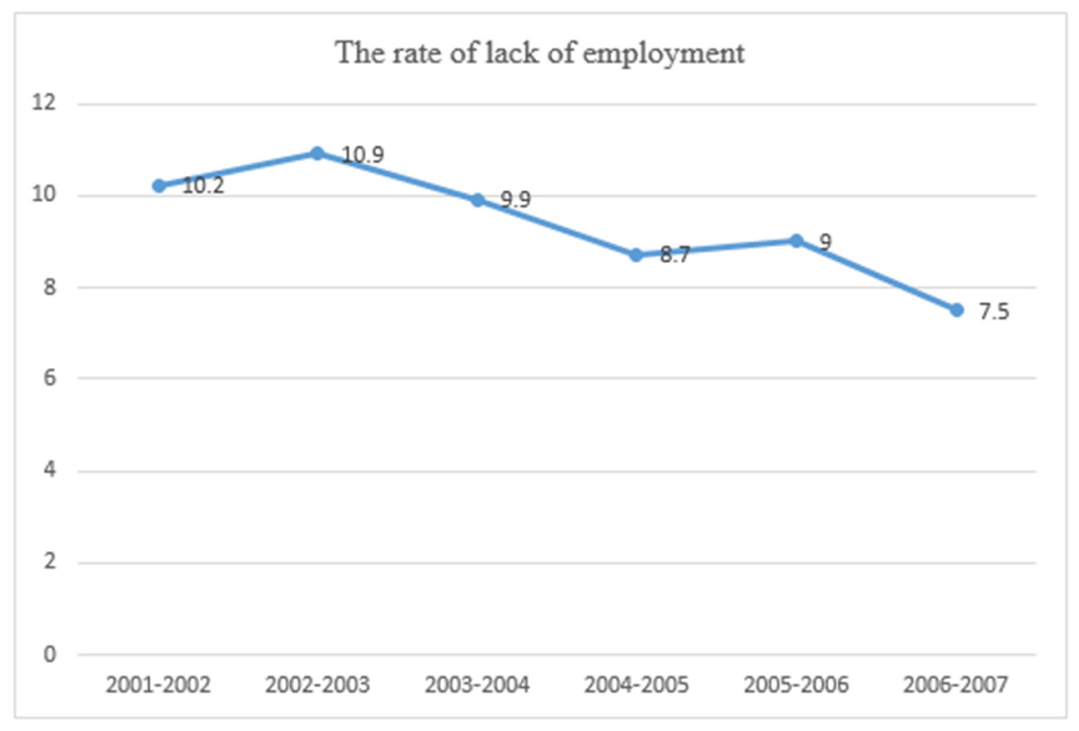

Figure 2 The rate of lack of employment.

As can be seen from figure 2, the lack of employment rate increased by 0.70 percent from 2002 to 2003 and decreased by one percent from 2003 to 2004. The rate declines drastically, reaching 7.5 percent from 2006 to 2007. The rate sometimes increases and sometimes drops, indicating the existence of fluctuation in the rate of lack of employment in India's economy. The trade-off between the rate of lack of employment and India's inflation rate from 2001-2007 in the short-Run.

Table 4. The rate of lack of employment and inflation in India.

\begin{tabular}{|c|c|c|}
\hline Years & The rate of lack of employment (percentage) & The rate of inflation (percentage) \\
\hline $2001-2002$ & 10.20 & 10.90 \\
\hline $2002-2003$ & 10.90 & 12.09 \\
\hline $2003-2004$ & 9.9 & 9.21 \\
\hline $2004-2005$ & 8.7 & 7.65 \\
\hline $2005-2006$ & 9.0 & 6.02 \\
\hline $2006-2007$ & 7.5 & 7.12 \\
\hline
\end{tabular}

Source: The Ministry Of Labor And Employment; India. 


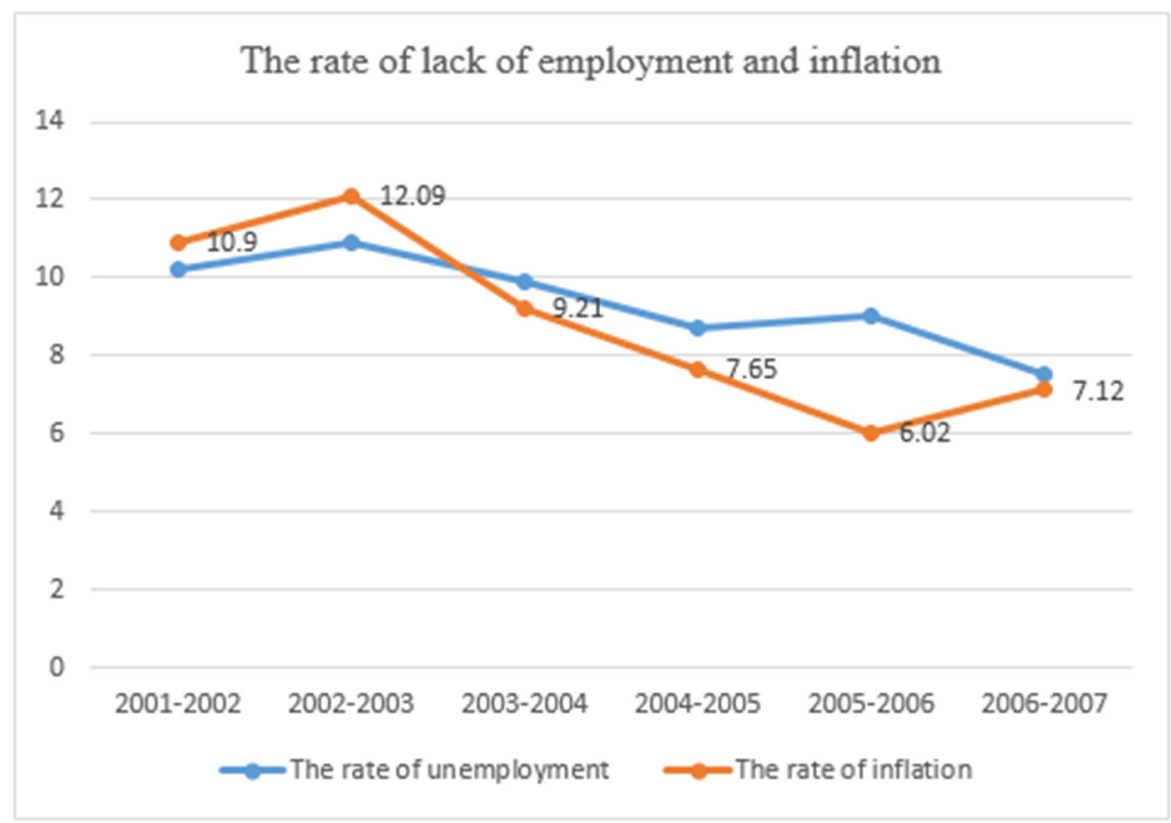

Figure 3 The rate of lack of employment and inflation in India.

Table 5. The relationship between the rate of lack of employment and the inflation rate in India

\begin{tabular}{|l|c|c|}
\hline Differences of the preceding year & $\begin{array}{c}\text { The rate of lack of employment } \\
\text { (percentage) }\end{array}$ & $\begin{array}{c}\text { The rate of inflation } \\
\text { (percentage) }\end{array}$ \\
\hline 2002 to 2003 and 2001 to 2002 & 0.7 & -2.88 \\
\hline 2003 to 2004 and 2002 to 2003 & -1 & -1.56 \\
\hline 2004 to 2005 and 2003 to 2004 & -1.2 & -1.63 \\
\hline 2005 to 2006 and 2004 to 2005 & 0.3 & 1.1 \\
\hline 2006 to 2007 and 2005 to 2006 & -1.5 & \\
\hline
\end{tabular}




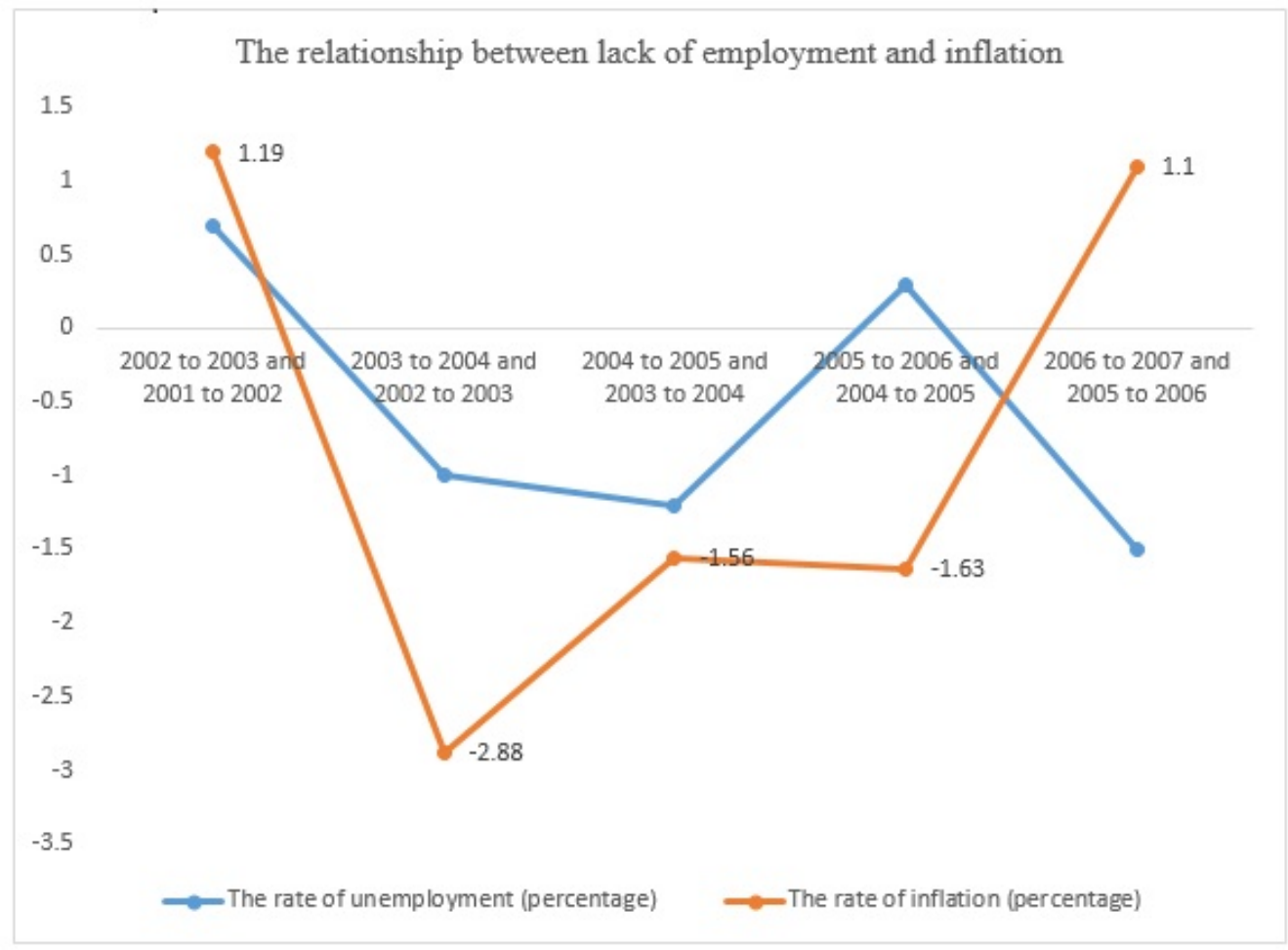

Figure 4 The link between the rate of lack of employment and inflation rate in the Indian economy.

Figure 3 illustrates the difference in the lack of employment and inflation in India between 2001 and 2007. The variation from 2002 to 2003 indicates that both variables' percentage has increased while it decreases from 2003 to 2004 [2]. From 2004 to 2005, both parameters declined, and from 2005 to 2006, inflation decreased while the lack of employment increased slowly. From 2006 to 2007, inflation has grown at a low rate, while lack of employment has declined. According to the data observed from the study, there does not exist the Philips curve in Indian comedy [4]. Therefore, the study concludes that there is no connection between the lack of employment and India's inflation rate. The trade-off between the lack of employment and inflation does not exist in the Indian economy in the short run. The research supports early studies about the lack of employment and inflation, which states that trade-off does not exist in developing counties.

\section{DISCUSSION}

The first theory shows a 76 percent variation in the employment rate due to GDP and the inflation rate. It explains that lack of employment has a significant impact on the inflation rate, and the GDP has an insignificant effect on inflation [2]. The second theory indicates the lack of employment rate, and the GDP influence a 96 percent fluctuation in the inflation rate. It confirms that a high inflation rate has a significant impact on a lack of employment, and the GDP has little effect on employment [6]. The third theory indicates a 95 percent variation in the GDP, which is influenced by inflation and lack of employment. It confirms that the GDP also significantly impacts the lack of employment, and inflation has little effect on employment [7]. However, the results show that the link between lack of employment, inflation, and the GDP influences each other at insubstantial levels. The findings support the null hypothesis; they also suggest that lack of employment is a crucial factor in India's economy. Inflation is one of the significant situations to consider when making calculated economic decisions.

Both the lack of employment and inflation problems in the economy affect ordinary citizens' standards of living. A low rate of lack of employment, price stability, and high production are the goals that every economy aims to achieve. Many studies show a trade-off between the lack of employment rate and the inflation rate in various countries in different periods in the short run. Therefore, it is recommended for Indian policymakers to focus their efforts on reorganizing the economy, employment level, and managing the instability in prices.

When prices increase, the value of money depreciates and leads to household incomes reducing. Lack of employment is the condition where the supply of human resources is greater than the demand for labor. The reverse correlation between the lack of employment and the inflation rate is shown in the Phillips curve; it is unstable in the short-run since it succeeds for a limited period [4]. Besides, some factors lead the curve to 
instability. The primary factor is the unexpected inflation where workers are motivated to demand higher wages due to the decline in employees' salaries.

Consequently, the lack of employment increases because businesses reduce their demand for labor. Therefore, inflation goes with an increase in the rate of lack of employment. Three wide measures evaluate macroeconomics' performance: the rate of inflation, the lack of employment rate, and the output's growth rate [6]. The link between changes in GDP growth rates and the lack of employment rate determines the rate of growth of potential output in the long-run.

\section{CONCLUSION}

The results show that lack of employment is statistically substantial when it comes to inflation. Inflation and lack of employment pose severe threats in any country's economy. Many economists show that in the effort to decrease, lack of employment may risk more inflation. However, some usually challenge the trade-off argument, arguing that it only works in the short-run [4]. Therefore, there needs to be strong collaboration among ministries that deal with inflation and lack of employment in India. Sellers usually use resources to modify prices when inflation occurs, and as a result, society's output decreases [2]. The challenge of lack of employment in India is influenced by the loss of output since unemployed people do not contribute to production. These people do not pay taxes, forcing taxpayers to bear their output costs. The study uses the Bi-variate regression model approach to determine if there exists a link between the rate of lack of employment and inflation in India [4]. The results support the null hypothesis that there is no substantial correlation between the inflation rate and India's lack of employment rate.

This article recommends several policy options for the Indian government. Firstly, the Government needs to Redesign the economy towards local growth rather than foreign ideas. Secondly, the government should develop advanced technology to generate more reliable employment and increase workers' wages efficiently. Then it should ensure adequate supervision of price instability. Besides, it should improve electricity, which will lead to the generation of employment.

\section{ACKNOWLEDGMENT}

I am thankful to all people that I have had the opportunity to work with during this research. Everyone I worked with gave me comprehensive professional and personal guidance where they have given me knowledge on the study and in life. Also, I would like to thank my professor Ascari, who has taught me a lot as my mentor and teacher. My family is also a big part of my pursuit of this project. I am grateful for my father, mother, and sister, who have provided me with guidance and love during this research.

\section{REFERENCES}

[1] L. Ball, A. Chari, \& P. Mishra. Understanding inflation in India (No. w22948). National Bureau of Economic Research. 2016.

[2] K. Chand, R. Tiwari, \& M. Phuyal. Economic Growth and Lack of employment Rate: An Empirical Study of Indian Economy. PRAGATI: Journal of Indian Economy, 2017, 4(2), 130-137.

[3] R. Chander. Impact of Inflation on GDP and Lack of employment Rate in India. Studies in Indian Place Names, 2020, 40(56), 2254-2260.

[4] M. Sahoo, \& J. Sahoo. The relationship between lack of employment and some macroeconomic variables: Empirical evidence from India. Theoretical \& Applied Economics, 2019, 26(1).

[5] A. Singh, \& A.K. Sharma. An empirical analysis of macroeconomic and bank-specific factors affecting the liquidity of Indian banks. Future Business Journal, 2016, 2(1), 40-53.

[6] D. Singh, \& N. Verma. The trade-off between inflation and lack of employment in the short run: A case of the Indian economy. International Finance and Banking, 2016, 3(1), 77-96.

[7] R. Singh. Impact of GDP and inflation on lack of employment rate:" A study of Indian economy in 2011-2018". International Journal of Management, IT and Engineering, 2018, 8(3), 329-340. 